\title{
Antibiogram of bacterial species isolated from canine pyometra
}

\author{
Varun Bassessar, Yamini Verma and Madhu Swamy \\ Department of Veterinary Pathology, \\ College of Veterinary Science and Animal Husbandry, \\ Nanaji Deshmukh Veterinary Science University (NDVSU), Jabalpur (M.P.), India \\ Corresponding author: Varun Bassessar, email:varun.vets@gmail.com \\ Received: 01-03-2013, Revised: 14-04-2013, Accepted: 14-04-2013, Published online: 01/06/2013
}

\section{How to cite this article:}

Bassessar V, Verma Y and Swamy M (2013) Antibiogram of bacterial species isolated from canine pyometra, Vet World 6(8): 546-549, doi: 10.5455/vetworld.2013.546-549

\begin{abstract}
Aim: The aim of the present work was to ascertain the bacterial flora causing pyometra in female dogs and their antibiotic sensitivity.

Materials and Methods: A study was conducted to determine the antibiogram of bacterial species isolated from 20 female dogs diagnosed with pyometra. The vaginal discharge was collected by sterile swab and streaked smoothly over Mueller Hinton medium and sensitivity towards antibiotics was determined by measuring the zone of inhibition using a Hi-media scale.

Results: The antobiogram showed that Gentamicin was the most sensitive (85\%) antibiotic followed by Enrofloxacin, Ciprofloxacin and Amoxicillin (65\%, 65\% and 55\%), respectively. The isolates were most resistant to Oxytetracycline (85\%) followed by Tetracycline, Ampicillin, Chloramphenicol, Cloxacillin and Erythromycin (80\%, 80\%, 75\%, 70\% and 70\%), respectively.
\end{abstract}

Conclusion: Gentamicin was found to be most effective antibiotic against the bacterial species isolated from canine pyometra.

Keywords: antibiotic, antibiogram, canine, pyometra, sensitivity test

\section{Introduction}

Canine pyometra, also known as cystic endometrial hyperplasia complex, is a disease of the adult dog with inflammation of the uterus and accumulation of pus, and normally occurs in the luteal phase of the oestrous cycle. Pyometra refers to uterine infection that occurs when contaminating bacteria overcome the normal uterine protective mechanisms. The bacterial infection is a secondary condition. Bacteria ascend through the cervix and into the uterus during oestrous. Bitches with cystic endometrial hyperplasia, seem to be incapable of eliminating bacteria that can survive in the cystic fluid. The toxic state affects the function of several organs like bone marrow, kidney, liver etc. [1].

It is of particular importance to the veterinary practitioner, since early recognition, diagnosis and appropriate intervention is required to avoid fatal consequences in animals [2]. Therefore, identification of the causative agent before institution of appropriate therapy is considered to be more rationale while treating this problem in female dogs.

\section{Materials and Methods}

Location of work and study period: The work was conducted in Department of Veterinary Pathology and Teaching Veterinary Clinical Service Complex

This article is an open access article licensed under the terms of the Creative Commons Attribution License (http://creativecommons org/licenses/by/2.0) which permits unrestricted use, distribution and reproduction in any medium, provided the work is properly cited.
(TVCC), College of Veterinary Science and Animal Husbandry, NDVSU, Jabalpur, Madhya Pradesh. The study period was of 8 months extending from January -August, 2009.

Collection of samples: Twenty female dogs with a presumptive diagnosis of pyometra, irrespective of their age or breed, were included in the study. The diagnosis was based on history, clinical examination, laboratory parameters and ultrasonography. Discharge material from the vagina of the pyometric animals was collected with the help of sterilized cotton swabs under aseptic conditions.

Processing of samples: The swabs were then processed for isolation of bacteria and antibiotic sensitivity test. The vaginal discharge was spread on simple and enriched media, and left for incubation at $37^{\circ} \mathrm{C}$ for a period of 24 to $48 \mathrm{hrs}$.

Materials used: Commercially available various ready to use dehydrated medias (Hi-Media Laboratories Limited, Mumbai, India) were used for the preparation of culture media.The following media were utilized during the present study:

Nutrient broth, Nutrient agar, MacConkey agar, Brilliant green agar, Eosinemethylene blue agar, Mannitol salt agar, Muller-Hinton agar, Sabouraud's agar

Antibiotic sensitivity test: Growth from isolated colonies was used for identification studies based on morphology, staining, cultural and biochemical charac- 
teristics [3]. The discharge material was streaked over Mueller Hinton medium in such a way that a smooth, homogenous lawn culture was obtained. Plates were allowed to dry for 5 to 10 minutes at room temperature after inoculation. Standard disc of 10 antibiotics (Himedia) were placed with the help of forceps and pressed gently to ensure full contact with the media. Plates were incubated at $37^{\circ} \mathrm{C}$ for 18 to $24 \mathrm{hrs}$. The inhibition zones of different antibiotics were recorded in $\mathrm{mm}$ and results were expressed in terms of sensitivity (S) and resistant (R). The sensitivity towards antibiotics was determined using the single disc diffusion method [3]. Zone of inhibition was measured using a Hi-media scale. Interpretation was made according to guidelines of clinical laboratory standards institute (CLSI, 2003) proposed for animal pathogens. Antibiotic discs used in the present study are as shown in Table-1.

Table-1. Antibiotics used for determination of the antibiogram of bacterial spp. isolated from canine pyometra.

\begin{tabular}{llc}
\hline Sr. No. & Name and concentration of antibiotic & Symbol \\
\hline 1 & Tetracycline $(30 \mu /$ disc $)$ & $\mathrm{T}$ \\
2 & Erythromycin (15mcg/disc) & $\mathrm{E}$ \\
3 & Ciprofloxacin (10mcg/disc) & $\mathrm{Cf}$ \\
4 & Enrofloxacin (10mcg/disc) & $\mathrm{E}$ \\
5 & Cloxacillin (5mcg/disc) & $\mathrm{Cx}$ \\
6 & Oxytetracycline $(30 \mathrm{mcg} / \mathrm{disc})$ & $\mathrm{O}$ \\
7 & Gentamicin (10mcg/disc) & $\mathrm{G}$ \\
8 & Chloramphenicol (30mcg/disc) & $\mathrm{C}$ \\
9 & Amoxicillin (10mcg/disc) & $\mathrm{Am}$ \\
10 & Ampicillin (10mcg/disc) & $\mathrm{A}$ \\
\hline
\end{tabular}

\section{Results}

The microbiological examination of the vaginal discharge from the 20 pyometric dogs revealed 9 samples of Escherichia. coli, 4 samples of Salmonella spp., 2 samples of Pseudomonas spp., 3 samples of Staphylococcus spp. and 2 samples of mixed infection with $E$. coli and Staphylococcus spp. The antibiogram of 20 vaginal discharge showed that Gentamicin (85\%) was the most sensitive antibiotic followed by Enrofloxacin (65\%). However, Ciprofloxacin and Amoxicillin showed 55\% sensitivity. The isolates were most resistant to Oxytetracycline (85\%), Tetracycline (80\%), Ampicillin (80\%), Chloramphenicol (75\%) Cloxacillin (70\%) and Erythromycin (70\%).

In in-vitro study, the isolates of $E$. coli were found to be $100 \%$ sensitive to the Gentamicin followed by Enrofloxacin (75\%), Ciprofloxacin (65\%), Amoxicillin (55\%). The organisms were most resistant to Tetracycline and oxytetracycline (100\%), respectively.

All the Staphylococus spp. Were most effective to Enrofloxacin (100\%) followed by Gentamicin, Erythromycin, Amoxicillin and Chloramphenicol (65\%), respectively, while the other antibiotics were ineffective against the obtained isolates.

Salmonella spp. isolates were effective to Gentamicin (75\%) and Amoxicillin (75\%), Ciprofloxacin (50\%) and Enrofloxacin $(50 \%)$, whereas Chloramphenicol $(0 \%)$ was least sensitive followed by Cloxacillin and Oxytetracycline (25\%), respectively.
Isolates of Pseudomonas spp. showed 50\% effectiveness in case of Gentamicin and Tetracycline, while complete resistance was seen in case of other antibiotics used.

\section{Discussion}

Several studies have been conducted to determine the antibiogram pattern of bacterial isolates from various infections in canines. The results vary with the geographical location of the work and the type of the bacteria isolated. In the present study E. coli were found to be most frequently associated with canine pyometra. Aminoglycosides like Gentamicin and Fluoroquinolone like Enrofloxacin were found to be most effective. However, since mixed infections were prevalent $100 \%$ efficacy of a single antibiotic was not observed.

Silva et al. [4] during their etiological and therapeutic study of pyometra in female dogs found that Gentamicin was the most effective in-vitro antibiotic (97.83\%) followed by Chloramphenicol $(75.51 \%)$ and Streptomycin (65.79\%), whereas Cephalosporin (14.81\%) was the least effective drug. Ball et al. [5] studied the antimicrobial resistance and prevalence of canine uropathogens. In the study they found that the bacterial isolates were most likely to be susceptible to Gentamicin, Fluoroquinolones, Amoxicillin-Clavulanic acid, Cephalosporins (third generation). However, Murugavel et al. [6] reported that the bacterial isolates from pyometra were sensitive to Ciprofloxacin only while they were resistant to Cephalexin, Gentamicin, Cloxacillin and tetracycline. Roy et al. [7] collected 234 genital swabs from canine genital infections including pyometra cases which yield 98 (41.8\%) Escherichia coli strains. Among these positive samples highest percentage (46.2) were observed from uterine infections (pyometra) cases. The antibiotic drugs like Gentamicin, Chloramphenicol, Cefixime (each 100\%), Ciproflo-xacin (90\%) were found to be sensitive against these isolates when tested for antibiogram in vitro. But Amikacin (95\%), Tetracycline, Kanamycin (approx. 80-82\%), Vancomycin, Erythromycin and Novobiocin (78-80\%) showed their infectivity against these isolates. Our study correlates with the reports of Ghoseet al. [8], Bhattacharya [9] and Chhabra and Arora [10].

Mane et al. [11] observed that the antibiotic sensitivity pattern to field isolates of $E$. coli showed considerable variation in sensitivity and resistance pattern. The workers found highest rate of resistance was against Tetracycline (80\%), followed by Doxycycline (70\%), Trimethoprim (55\%), Ampicillin (50\%), Amoxicillin (40\%) and Ciprofloxacin (40\%). Ghanbarpour and Akhtardanesh [12] reported that eighty four isolates of $E$. coli from canine pyometra exhibited the maximum resistance against Sulfadiazine and Tetracycline. Similarly, resistance to Amoxicillin, Cloxacillin and Tetracycline by E. coli in colibacillosis has been observed [13] in Japanese Quails. Hariharan et al. [14] employing 1819 samples from canine otitis reported all $178 \mathrm{E}$. coli isolates to be susceptible to 
Table-2. Overall sensitivity and resistance profiles of of bacterial spp. isolated from canine pyometra

\begin{tabular}{|c|c|c|c|c|c|}
\hline Sr. No. & $\begin{array}{lr}\text { Antibiotics } & \mathbf{N} \\
& \text { ser } \\
& \text { isc }\end{array}$ & $\begin{array}{l}\text { No. of } \\
\text { ensitive } \\
\text { solates }\end{array}$ & $\begin{array}{c}\text { Sensitivity } \\
\%\end{array}$ & $\begin{array}{l}\text { No. of } \\
\text { resistant } \\
\text { isolates }\end{array}$ & $\begin{array}{c}\text { Resistance } \\
\%\end{array}$ \\
\hline 1 & $\begin{array}{l}\text { Tetracycline } \\
(30 \mu \mathrm{g} / \text { disc })\end{array}$ & 5 & $25 \%$ & 15 & $75 \%$ \\
\hline 2 & $\begin{array}{l}\text { Erythromycin } \\
\text { (15 } \mu \mathrm{g} / \text { disc) }\end{array}$ & 6 & $30 \%$ & 14 & $70 \%$ \\
\hline 3 & $\begin{array}{l}\text { Ciprofloxacin } \\
\text { (10 } \mu \mathrm{g} / \text { disc) }\end{array}$ & 11 & $55 \%$ & 9 & $45 \%$ \\
\hline 4 & $\begin{array}{l}\text { Enrofloxacin } \\
\text { (10 } \mu \mathrm{g} / \text { disc })\end{array}$ & 13 & $65 \%$ & 7 & $35 \%$ \\
\hline 5 & $\begin{array}{l}\text { Cloxacillin } \\
(5 \mu \mathrm{g} / \text { disc })\end{array}$ & 6 & $30 \%$ & 14 & $70 \%$ \\
\hline 6 & $\begin{array}{l}\text { Oxytetracycline } \\
\text { (30 } \mu \mathrm{g} / \mathrm{disc})\end{array}$ & 3 & $15 \%$ & 17 & $85 \%$ \\
\hline 7 & $\begin{array}{l}\text { Gentamicin } \\
(10 \mu \mathrm{g} / \mathrm{disc})\end{array}$ & 17 & $85 \%$ & 3 & $15 \%$ \\
\hline 8 & $\begin{array}{l}\text { Chloramphenico } \\
\text { (30 } \mathrm{\mu g} / \mathrm{disc})\end{array}$ & col 5 & $25 \%$ & 15 & $75 \%$ \\
\hline 9 & $\begin{array}{l}\text { Amoxicillin } \\
(10 \mu \mathrm{g} / \mathrm{disc})\end{array}$ & 11 & $55 \%$ & 9 & $45 \%$ \\
\hline 10 & $\begin{array}{l}\text { Ampicillin } \\
(10 \mu \mathrm{g} / \mathrm{disc})\end{array}$ & 4 & $20 \%$ & 16 & $80 \%$ \\
\hline
\end{tabular}

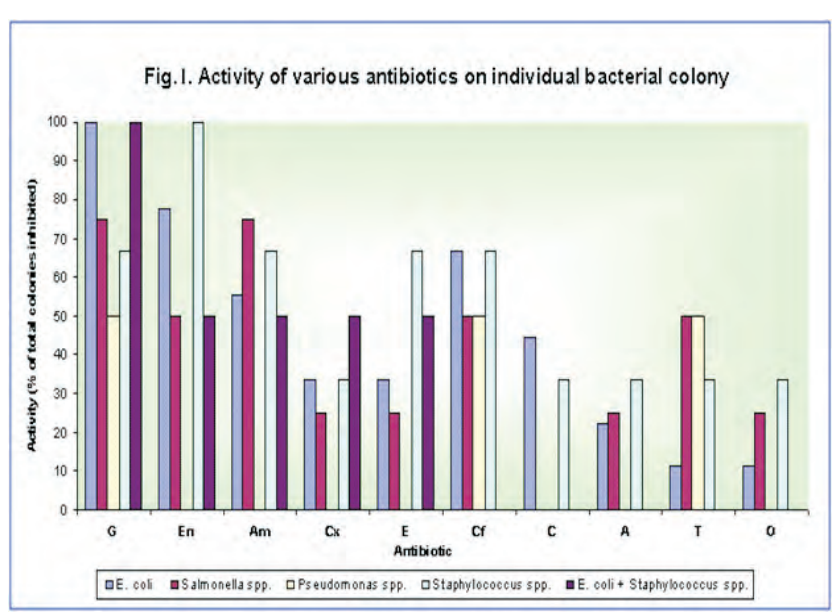

Amikacin, Cefotaxime, Chloramphenicol and Ceftriaxone. Rajeev et al. [15] isolated E. coli and $S$. aureus and found that the antibiogram profile of them is highly variable. Chloramphenicol and Enrofloxacin were found to be promising antibiotics as most of the isolates were sensitive to them. These results correlated with the findings of Wani and Bhat [16], Balakrishnan et al. [17], Palinivel et al. [18] and Anderson et al. [19] who observed high sensitivity of $E$. coli serotypes to Chloramphenicol, Amikacin and Enrofloxacin. Ramani Pushpa et al. [20] reported that out of 10 E. coli isolates about $87.5 \%$ were sensitive to Cephalexin, $79.6 \%$ to Chloramphenicol, $58.6 \%$ to Ciprofloxacin, $52.6 \%$ to Enrofloxacin and $52.6 \%$ to Gentamicin. Shambulingappa and Anand Manegar [21] conducted studies on clinical metritis in female dogs and found Gram negative bacteria in $54.05 \%$ cases and major isolates were E. coli (18.92\%) and Proteus spp. $(16.22 \%)$. Major gram positive isolates were $S$. aureus $(24.32 \%)$ and S. pyogenes $(10.18 \%)$. Majority of the above isolates were highly sensitive to Ciprofloxacin and Gentamicin. Lowered sensitivity was noticed towards Ampicillin, Streptomycin and Nitrofurantoin. In agreement to the findings of several workers, in the
Table-3. Antibiotic sensitivity and resistance profiles of bacterial spp. isolated from canine pyometra

\begin{tabular}{lllllllllllll}
\hline Name of bacteria & $\begin{array}{c}\text { No. of } \\
\text { isolates }\end{array}$ & \multicolumn{6}{c}{$\begin{array}{c}\text { Number of bacterial isolates found } \\
\text { sensitive to the antibiotic discs }\end{array}$} \\
\cline { 2 - 11 } & & G & En & Am & Cx & E & Cf & C & A & T & O \\
\hline E. coli & 9 & 9 & 7 & 5 & 3 & 3 & 6 & 4 & 2 & 1 & 1 \\
Salmonella Spp. & 4 & 3 & 2 & 3 & 1 & 1 & 2 & 0 & 1 & 2 & 1 \\
Pseudomonas Spp. & 2 & 1 & 0 & 0 & 0 & 0 & 1 & 0 & 0 & 1 & 0 \\
Staphylococcus Spp. & 3 & 2 & 3 & 2 & 1 & 2 & 2 & 1 & 1 & 1 & 1 \\
E. coli +Staphylococcus & 2 & 2 & 1 & 1 & 1 & 1 & 0 & 0 & 0 & 0 & 0 \\
Spp. & & & & & & & & & & & \\
\hline
\end{tabular}

G - Gentamicin, En - Enrofloxacin, Am - Amoxicillin, Cx - Cloxacillin, E - Erythromycin, Cf - Ciprofloxacin, C - Chloramphenicol, A - Ampicillin, $\mathrm{T}$ - Tetracycline, $\mathrm{O}$ - Oxytetracycline

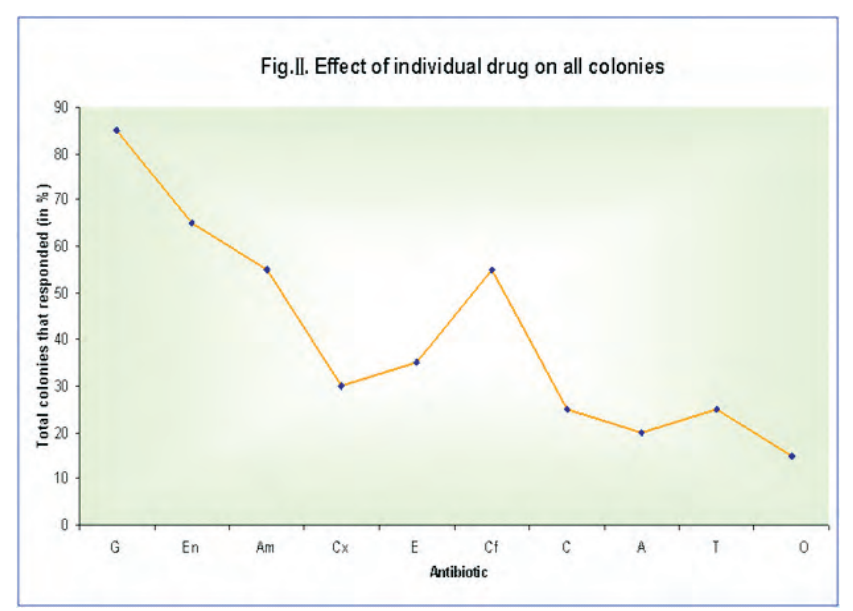

present study also, maximum sensitivity of $E$. coli was found to Gentamicin (85\%) followed by Enrofloxacin and the organisms were most resistant to Tetracycline and Oxytetracycline.

Maity, et al. [22] found that Staphylococcus spp. was the predominant one $(44.19 \%)$ from 43 canine pyometra cases screened in veterinary clinics. All the isolates were sensitive to Enrofloxacin, Ciprofloxacin, Gentamicin and Ceftriaxone, but were generally resistant to Lincomycin and Oxytetracycline. Thus, our findings are in agreement with those of earlier workers, with 100\% efficacy of Enrofloxacin observed against Staphylococcus spp.

In a study carried out to screen and analyze the characteristics of antibiotic resistance in Salmonella strains isolated from foods of animal origin the Salmonella isolates were found to be resistant against Trimetoprim, Kanamycin, and Co-trimoxazole [23]. However in agreement to our findings the workers reported efficacy of Gentamicin against Salmonella isolates. The bacterial profile of some isolates exhibited antibacterial resistance due to the antibacterial residue in the female dogs and indiscriminate use of antibiotics in the previous cases of illness without performing the 
antibiotic sensitivity test in female dogs.

\section{Conclusion}

Thus, it can be concluded that gentamicin was found to be the most effective antibiotic against bacteria like E. coli, Staphylococcus spp. and Salmonella spp. causing canine pyometra in this region whereas tetracycline and oxytetracycline were the least effective.

\section{Authors' contributions}

This study was a part of postgraduate thesis of VB, submitted to Department of Veterinary Pathology, Veterinary College, Jabalpur. All the authors contributed equally in design of the research, analysis of the data, drafting and revision of the manuscript. All authors read and approved the final manuscript.

\section{Acknowledgements}

Authors are thankful to The Vice Chancellor, Nanaji Deshmukh Veterinary Science University and Dean, Veterinary College, Jabalpur (M.P.) for providing necessary research facilities and fund.

\section{Competing interests}

The authors declare that they have no competing interests.

\section{References}

1. Kustritz, M. V. R. (2005) Cystic endometrial hyperplasia and pyometra. In: S.G. Ettinger and E.C. Feldman (ed.) Textbook of Veterinary Internal Medicine. $6^{\text {th }}$ edn.,Pubu., Elsevier Saunders, St. Louis, pp 1676-1680.

2. Smith, F. O. (2006) Canine pyometra. Theriogenology. 66: $610-612$.

3. Cruickshank, R., Dugie, J. P., Marimon, B. P. and Swain, R. H. A. (1975) Medical Microbiology, $12^{\text {th }}$ edn, Publ. Churchill Livingstone, New York. pp. 202-203.

4. Silva, L. B. G., Castro-Junior, I. F., Cunha, A. P., Mota, R. A., Silva, K. P. C. and Pinheiro-Junior, J. W. (2004) Aetiological and therapeutic study of pyometra in bitches from the metropolitian region of Recife. Pernambuco State, Brazil. $A$. Hora. Veterinaria., 24(139): 37-39.

5. Ball, K. R., Joseph, E., Rubin, M., Chirino-Trejo and Patricia, M. D. (2008) Antimicrobial resistance and prevalence of canine uropathogens at the Western College of Veterinary Medicine Veterinary Teaching Hospital, 2002-2007. Can. Vet. J., 49(10): 985-990.

6. Murugavel, K., Senthil Kumar, P. and Alphonse, R. M. D. (2001) Pyometra in Doberman bitch. Indian J. Anim. Repro., 22:91-93.
7. Roy, S. K., Das, B. and Batabyal, K. (2009) Antibiogram of pathogenic Escherichia coli isolated from canine pyometra cases. Journal of Inter academicia. 13 (4): 481-483.

8. Ghose, B., Sharda, R. Chabra, D. and Sharma, V. (2003) Occurrence of clinical and subclinical mastitis in buffaloes in the State of Haryana. ibid., 80:499.

9. Bhattacharya, A. (2002) Etiology and antibiotic spectra of bacterial isolates from field cases of mastitis in cases from Tripura district.Indian Vet. J., 79: 961.

10. Chhabra, D. and Arora, S. (2006) Antibiogram of Staphylococcus aureus isolated from bovine mastitis. Indian Vet. J., 83: 1333.

11. Mane, D. V., Patil, M. U. and Sawale, G. K. (2012) Antimicrobial drug resistance pattern of $E$. coli isolated from commercial chickens. Indian Vet. J., 89(6): 12-14.

12. Ghanbarpour, R. and Akhtardanesh, B. (2012) Genotype and antibiotic resistance profile of Escherichia coli strains involved in canine pyometra. Comparative Clinical Pathology. 21(5): 737-744.

13. Roy, P., Purushothaman, V., Koteeswaran, A. and Dhillon, A. S. (2006) A study on bacterial flora and antibacterial resistance of yolk sac infection in Japanese quail. J. Appl. Poult. Res., 15: 442.

14. Hariharan, H., Cooles, M., Poole, D., Lund, L and Page, R (2006) Update on antimicrobial susceptibilities of bacterial isolates from canine and feline otitisexterna. Can. Vet. J. 47: 252.

15. Rajeev, N. K., Isloor, S., Das, P. K. and Rathnamma, D. (2010) A dendrogram based analysis of antibiogram of $S$. aureus and E. coli isolates from bovine mastitis. Indian Vet. J., 87: 107-110.

16. Wani, S. A. and Bhat, M. A. (2003) An epidemiological study on bovine mastitis in Kashmir valley. Indian Vet. J., 80: 841.

17. Balakrishnan, G., Madhavan, U., Dorairajan, N. and Subramanian, M. (2004) Studies on bovine mastitis at Namakkal. Indian Vet. J., 81: 1166.

18. Palinivel, K. M., Selvasubramanian, S. and Nedunchellayan, S. (2005) Treatment of clinical mastitis with cefaquinome. Indian Vet. J., 82: 1313.

19. Anderson, K.L., Lyman, R.L., Bodeis Jones, S.M. and White, D. G. (2006) Genetic diversity and antimicrobial susceptibility profiles among mastitis-causing Staphylococcus aureus isolated from bovine milk samples. Am. J. Vet. Res., 67: 1185 .

20. RamaniPushpa, R. N., Thangavel, K., and Anandkumar, P. (2010) Bacterial etiology and antibiogram of clinical mastitis. Indian Vet. J., 87: 187-188.

21. Shambulingappa, B. E. and Anand Manegar, G. (2010) Aerobic bacterial flora and antibiogram profile in canine metritis. Indian Vet. J., 87: 556-558.

22. Maity, S., Sarkar, S. and Saha, T. (2009) Bacteriology and antibiogram of canine pyometra. Indian Vet. J., 86: 896-897.

23. Sharma, I. and Bist, B. (2013) Antibiotic sensitivity of Salmonella isolated from retail raw meats of goat, pig and poultry. Indian Vet. J., 90 (1): 42-43. 